\title{
Evaluation of secondary metabolites from the red sea tunicate Polyclinum Constellatum
}

\begin{abstract}
Chemical investigation of the Red Sea tunicate Polyclinum constellatum afforded nine compounds, identified as thymidine (1), uridine (2), adenosine (3), inosine (4), 24-methylene cholesterol (5), dihydrocholesterol (6), cholesterol (7), oleic acid (8) and 1,3-palmityl-2-palmitoleoylglycerol (9). All compounds isolated for the first time from the genus polyclinum. Acetylation of compounds 1, 2, 3, 4 and 5 yielded thymidine $3^{\prime}, 5^{`}$-diacetate (1-Ac), uridine $2^{\prime}, 3^{\prime}, 5^{`}$-triacetate $(2-\mathrm{Ac})$, adenosine $22^{\prime}, 3^{\prime}, 5^{\prime}$-triacetate (3-Ac), inosine $2^{\prime}, 3^{\prime}, 5^{\prime}$-triacetate (2-Ac) and 24-methylene cholesterol-3-acetate (5$\mathrm{Ac})$, respectively. Compound 5 showed potent antitrypanocidal activity with $\mathrm{IC}_{50}$ and $\mathrm{IC}_{90}$ values of 3.39 and $6.69 \mu \mathrm{g} / \mathrm{mL}$, comparable to $\alpha$-difluoromethylornithine (3.58 and $8.53 \mu \mathrm{g} / \mathrm{mL}$ ). The overall findings of the present study have shown that the Red Sea tunicate Polyclinum constellatum revealed different varieties of secondary metabolites with antiprotozoal and cytotoxic activities.
\end{abstract}

Keywords: red sea, tunicate, polyclinum constellatum, antimicrobial, antimalarial, antiprotozoal, cytotoxicity, acetylation of compounds, metabolites, cellulose, appendicularia, natural products
Volume 5 Issue 3 - 2017

\author{
Ali E Raslan, ${ }^{1,2}$ Mohamed M Radwan, ${ }^{1,3}$ \\ Safwat A Ahmed, ${ }^{4}$ Alaa M Nafady, ${ }^{2}$ Amira \\ SWanas, ${ }^{1,5}$ Babu Tekwani, ${ }^{1,6}$ Hashim A \\ Hassanean, ${ }^{4}$ Mahmoud A ElSohly ${ }^{1,7}$ \\ 'National Center for Natural Products Research, School of \\ Pharmacy, University of Mississippi, USA \\ ${ }^{2}$ Department of Pharmacognosy, Faculty of Pharmacy,Al-Azhar \\ University, Egypt \\ ${ }^{3}$ Department of Pharmacognosy, Faculty of Pharmacy, Alexandria \\ University, Egypt \\ ${ }^{4}$ Department of Pharmacognosy, Faculty of Pharmacy, Suez \\ Canal University, Egypt \\ ${ }^{5}$ Department of Pharmacognosy, Faculty of Pharmacy, Minia \\ University, Egypt \\ ${ }^{6}$ Department of Bimolecular Sciences, School of Pharmacy, \\ University of Mississippi, USA \\ ${ }^{7}$ Department of Pharmaceutics and Drug Delivery, School of \\ Pharmacy, University of Mississippi, USA
}

Correspondence: Mohamed M Radwan, National Center for Natural Products Research, School of Pharmacy, University of Mississippi, USA, Tel + |6629|5|708, Fax + |6629|55287, Emailmradwan@olemiss.edu

Received: May 02, 2017 | Published: May 26, 2017
Abbreviations: ' $\mathrm{H}$ NMR, proton nuclear magnetic resonance; ${ }^{13} \mathrm{C}$ NMR, carbon nuclear magnetic resonance; $2 \mathrm{D}$, two dimension; $\delta$, chemical shifts; s, singlet; d, doublet; dd, doublet of doublet; t, triplet; m, multiplet; $J$, coupling constant; Hz, hertz; HRESIMS, high resolution electrospray ionization mass spectrometry; GC/ MS, gas chromatographic mass spectrometry; $\mathrm{m} / \mathrm{z}$, mass to charge ratio; $\mathrm{MeOH}$, methanol; EtOAc, ethyl acetate; $\mathrm{CH}_{2} \mathrm{Cl}_{2}$, methylene chloride; $\mathrm{CHCl}_{3}$, chloroform; $\mathrm{HCl}$, hydrochloric acid; $\mathrm{DFMO}$, $\alpha$-difluoromethylornithine; Ac, acetyl; min, minute(s); h, hour(s) THP-1, human monocytic cell line derived from an acute monocytic leukemia patient; $\mathrm{IC}_{50}$, concentration that afford $50 \%$ inhibition; $\mathrm{IC}_{90}$, concentration that afford $90 \%$ inhibition

\section{Introduction}

Tunicates are marine invertebrate animals (animals lacking a backbone) that are commonly found attached to rocks, they are three main groups, sessile ascidians, pelagic appendicularians and thaliaceans. ${ }^{1}$ They are characterized by the possession of a tunic composed of cellulose. ${ }^{1}$ Adult tunicates are filter feeders: the seawater enters a pharynx through an inhalating or oral siphon, in most cases set in motion by ciliary beating, food particles are trapped on a mucous net secreted by the endostyle, and the water and waste exit the body through an exhalating or atrial siphon. ${ }^{1}$ Appendicularia, ascidians and some thaliaceans possess a tadpole-like larva with a notochord and metamorphose into sessile adults in the case of ascidians. Tunicates have reversible blood flow. ${ }^{1}$ Natural products found in tunicate has began to attract many chemist's interests; alkaloids, carotenoids, macrolides and tunichromes. ${ }^{2}$ The cytotoxic and antibacterial activities of Polyclinum indicum and Polyclinum madrasensis extracts have been tested at various concentrations and showed the results of highest cytotoxicity assay conducted, indicating the presence of cytotoxic compounds in these ascidians. ${ }^{3,4}$ The crude extract of ascidian Polyclinum madrasensis showed hemolytic properties against human, cow, goat and chicken bloods that be considered a valuable source for secondary metabolites which could be of pharmaceutical interest. ${ }^{5}$ Polyclinal a sulfated polyhydroxy benzaldehyde has been isolated from extracts of the temperate colonial ascidian Polyclinum planum. ${ }^{6}$ The highest concentration of this metabolite was found in the zooid-rich outer layers of this ascidian suggesting that it may represent a potential chemical defense against predators. ${ }^{6}$ As part of our research dealing with the isolation and biological evaluation of active compounds from marine origin, the chemistry and the biological properties of the tunicate Polyclinum constellatum collected from the Red Sea was investigated, which led to the isolation of nine compounds (1-9), for the first time from the genus polyclinum.

\section{Materials and methods}

\section{General experimental procedures}

${ }^{1} \mathrm{H}-\mathrm{NMR},{ }^{13} \mathrm{C}-\mathrm{NMR}$ and 2D-NMR spectra were recorded using the residual solvent signal as an internal standard on Bruker BioSpin Gm bH 400 and 500 spectrometers (Bruker, Rheinstetten, Germany). High resolution mass spectrometry were measured using a Bruker BioApex FT mass spectrometer (Bruker, Rheinstetten, Germany). GC/MS analysis was carried out using an HP 6890 series GC (Agilent 
Technologies, Santa Clara, CA, USA), equipped with a split/splitless capillary injector, an HP 6890 series injector autosampler and an Agliant DB-5ms column ( $30 \mathrm{mx} 0.25 \mathrm{~mm} \times 0.25 \mu \mathrm{m})$, interfaced to a HP 5973 mass selective detector (MSD). The injector temperature was $250^{\circ} \mathrm{C}$, and $1 \mu \mathrm{L}$ of sample was injected in the splitless mode, with the splitless time set at $60 \mathrm{~s}$, the split flow set at $50 \mathrm{~mL} / \mathrm{min}$ and the septum purge valve set to close $60 \mathrm{~s}$ after the injection occurred. The oven temperature was raised from 70 to $270^{\circ} \mathrm{C}$ (held for $20 \mathrm{~min}$ ) at a rate of $5^{\circ} \mathrm{C} / \mathrm{min}$, for a total run time of $60 \mathrm{~min}$; the transfer line temperature was $280^{\circ} \mathrm{C}$. Chemicals for the pharmacological studies were purchased from Sigma-Aldrich (St. Louis, MO, USA) except the fetal bovine serum (Midwest Scientific, Valley Park, MO, USA) and the Bio-rad Bradford dye (Fisher Scientific, Pittsburg, PA, USA).

\section{Tunicate material, collection and identification}

The tunicate Polyclinum constellatum (coll. no. SAA-117) was collected in June, 2015 at depths between 10 and $20 \mathrm{~m}$ from the Egyptian Red Sea coast at Safaga. The sample was identified by Dr Tarek Temraz, Marine Science Department, Faculty of Science, Suez Canal University, Ismailia, The sample was directly frozen after collection and stored at $-20^{\circ} \mathrm{C}$. A voucher specimen was kept at the Department of Pharmacognosy, Faculty of Pharmacy, Suez Canal University, Ismailia, Egypt, under a registration no. SAA-117.

\section{Extraction and isolation}

The fresh material $(0.5 \mathrm{~kg})$ was frozen after collection. It was chopped while frozen into small pieces and extracted with $\mathrm{MeOH}$ $(500 \mathrm{mLx} 3)$ at room temperature. The crude extract was concentrated till dryness under reduced pressure to give a dark green viscous crude extract (3.86g). A $3.25 \mathrm{~g}$ of the extract was subjected to fractionation by vacuum liquid chromatography over a silica gel column $(100 \mathrm{~g}$, $9 \mathrm{~cm} \times 30 \mathrm{~cm})$ eluted with hexanes/EtOAc $(75: 25,0: 100)$ followed by each EtOAc/MeOH (50:50, 0:100) yielding 4 fractions. Fraction $2(455.5 \mathrm{mg})$ was purified on silica gel column $(20 \mathrm{~g}, 34 \mathrm{~cm} \times 2 \mathrm{~cm})$ and eluted with hexanes/EtOAc in gradient manner from $5 \%$ to $20 \%$ to yield three subfractions $(2 \mathrm{~A}-2 \mathrm{C})$. Subraction $2 \mathrm{~A}(90.6 \mathrm{mg})$ was further purified on silica gel column $(5 \mathrm{~g}, 25 \mathrm{~cm} \times 0.8 \mathrm{~cm})$ using hexanes/EtOAc (95:5) to give compound 9 (15.6mg). Subraction 2B (202.4mg) was further purified on an amino column followed by silica gel column $(8 \mathrm{~g}, 25 \mathrm{~cm} \times 0.8 \mathrm{~cm})$ eluted with hexanes/EtOAc in gradient manner and a RP column $(10 \mathrm{~g}, 25 \mathrm{~cm}$ x $0.8 \mathrm{~cm})$ using $\mathrm{MeOH} /$ $\mathrm{H}_{2} \mathrm{O}(97.5: 2.5)$ to yield compounds $5(12.1 \mathrm{mg}), 6(18.8 \mathrm{mg})$ and 7 $(4.2 \mathrm{mg})$. Fraction $3(148.3 \mathrm{~g})$ was subjected to silica gel column $(7 \mathrm{~g}$, $25 \mathrm{cmx} 0.8 \mathrm{~cm}$ ) eluted with $\mathrm{CH}_{2} \mathrm{Cl}_{2} / \mathrm{MeOH}$ (98:2) yielding compound $8(20.5 \mathrm{mg})$. Fraction $4(2.2 \mathrm{~g})$ was subjected to silica gel column $(80 \mathrm{~g}, 46 \mathrm{~cm} \times 2.5 \mathrm{~cm})$ eluted with $\left(\mathrm{CH}_{2} \mathrm{Cl}_{2} / \mathrm{MeOH}, 98: 2\right)$ to give four subfractions (4A-4D). Subfraction $4 \mathrm{~B}(35.5 \mathrm{mg})$ was subjected to silica gel column ( $2 \mathrm{~g}, 25 \mathrm{~cm} \times 0.8 \mathrm{~cm})$ using $\mathrm{CHCl}_{3} / \mathrm{MeOH} / \mathrm{H}_{2} \mathrm{O}(15: 6: 1)$ as a mobile phase followed by a RP column $(10 \mathrm{~g}, 25 \mathrm{~cm} \times 0.8 \mathrm{~cm})$ using $\mathrm{MeOH} / \mathrm{H}_{2} \mathrm{O}(50: 50)$ to give compound $1(21.3 \mathrm{mg})$. Subfraction $4 \mathrm{C}$ $687.1 \mathrm{mg})$ was subjected to silica gel column $(28 \mathrm{~g}, 34 \mathrm{~cm} \times 2 \mathrm{~cm})$ eluted with $\mathrm{CHCl}_{3} / \mathrm{MeOH} / \mathrm{H}_{2} \mathrm{O}(15: 6: 1)$ to yield two fractions (4C1 and 4C-2). Fraction 4C-1 (554.6mg) was subjected to sephadex LH-20 $(100 \mathrm{~g}, 46 \mathrm{~cm} \times 2.5 \mathrm{~cm})$ using $\mathrm{MeOH}$ as an eluent yielding two subfractions (4C-1-1 and 4C-1-2). Subfraction 4C-1-1 (113.4mg) was purified on a silica gel column $(5 \mathrm{~g}, 25 \mathrm{~cm} \times 0.8 \mathrm{~cm})$ using $\mathrm{CHCl}_{3} /$ $\mathrm{MeOH} / \mathrm{H}_{2} \mathrm{O}$ (15:6:1) as a mobile phase to yield compound 2(24.4mg). Subfraction 4C-1-2(20.3mg) was subjected to sephadex LH-20 (100g, $46 \mathrm{~cm} \times 2.5 \mathrm{~cm})$ using $\mathrm{MeOH}$ as an eluent to give compound $3(2.2 \mathrm{mg})$. Fraction $4 \mathrm{C}-2(132.5 \mathrm{mg})$ was subjected to silica gel column (6g, $25 \mathrm{~cm} \times 0.8 \mathrm{~cm}$ ) eluted with $\mathrm{CHCl}_{3} / \mathrm{MeOH} / \mathrm{H}_{2} \mathrm{O}(15: 6: 1)$ followed by sephadex LH-20 (100g, $46 \mathrm{~cm} \times 2.5 \mathrm{~cm})$ to give compound $4(17.2 \mathrm{mg})$ (Scheme 1).

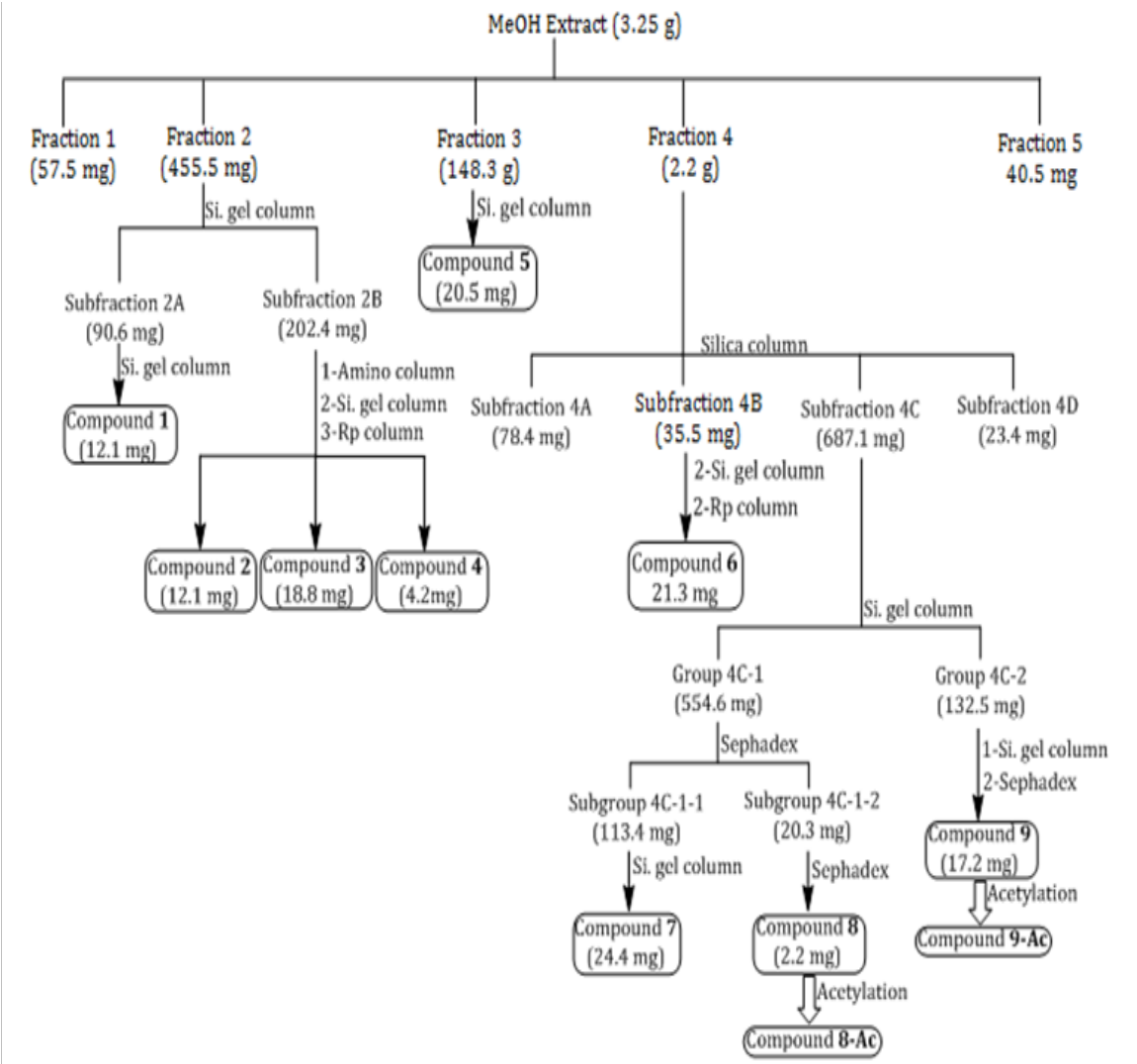

Scheme I Isolation of the compounds I-9 from the red sea tunicate polyclinum constellatum. 


\section{Acetylation of compounds I, 2, 3, 4 and 5:}

A $2 \mathrm{mg}$ of each compound was dissolved in $1 \mathrm{~mL}$ of pyridine and then $2 \mathrm{~mL}$ of acetic anhydride was added. The reaction mixture was kept at room temperature for $12 \mathrm{~h} .{ }^{7}$ The solvent was evaporated under vacuum to give compounds 1-Ac, 2-Ac, 3-Ac, 4-Ac and 5-Ac.

\section{Esterfication of compound 8:}

Compound $8(4 \mathrm{mg})$ was dissolved in $1 \mathrm{~mL}$ of chloroform followed by addition of $1 \mathrm{~mL}$ of $20 \mathrm{mM}$ cupric acetate monohydrate in methanol and $5 \mathrm{~mL}$ of $0.5 \mathrm{~N} \mathrm{HCl}$ in methanol. The mixture was stored for $60 \mathrm{~min}$ at room temperature, and then extracted with $10 \mathrm{~mL}$ of chloroform after addition of $10 \mathrm{~mL}$ of water. ${ }^{8}$ The pooled chloroformic extract was washed with water and then evaporated to dryness under a flow of nitrogen to give the corresponding fatty acid methyl ester of compounds 8 .

\section{Acid hydrolysis of compound 9:}

Compound $9(3 \mathrm{mg})$ was added to $2 \mathrm{~mL}$ of $1.2 \% \mathrm{HCl} / \mathrm{MeOH}$ and then stored for $20 \mathrm{~min}$ at $45^{\circ} \mathrm{C}$. The solution was extracted with hexanes $(5 \mathrm{~mL})$. The fatty acid methyl esters in the hexanes layer were identified by GC/MS. ${ }^{9}$

\section{In vitro antiprotozoal assay:}

All compounds were tested for their antiprotozoal activities against Leishmania donovani promastigote, L. donovani axenic amastigotes, intracellular L. donovani amastigotes/THP1 cells and Trypanosoma brucei..$^{10}$ The assays have been adapted to 384 well microplate format. In a 384 well micro-plate, the samples with appropriate dilution were added to the cultures of protozoan cells $(2 \times 106 \mathrm{cell} / \mathrm{mL})$. The plates were incubated at $26^{\circ} \mathrm{C}$ for $72 \mathrm{~h}\left(37^{\circ} \mathrm{C}\right.$ for axenic amastigotes and $T$. brucei trypomastigotes) and growth of the parasites in cultures were determined by Alamar Blue assay. ${ }^{10,11}$ The compounds were tested at concentrations ranging from $0.4-10 \mu \mathrm{g} / \mathrm{mL}$. The compounds were also tested against $L$. donovani intracellular amastigotes in THP1 cells employing a parasite-rescue and transformation assay. ${ }^{12}$ Pentamidine and Amphoterecin B were tested as the standard antileishmanial agents. DFMO ( $\alpha$-difluoromethylornithine) was tested as a positive control for antitrypanosomal activity. $\mathrm{IC}_{50}$ and $\mathrm{IC}_{90}$ values were computed from dose-response curves using XLfit software.

\section{In vitro antimicrobial assay:}

All organisms used for the biological evaluation were obtained from the American Type Culture Collection (Manassas, VA, USA) and including the fungi Candida albicans ATCC 90028, Candida glabrata ATCC 90030, Candida krusei ATCC 6258, Cryptococcus neoformans ATCC 90113, and Aspergillus fumigatus ATCC 90906 and the bacteria methicillin-resistant $S$. aureus ATCC 43300 (MRSa), Escherichia coli ATCC 35218, Pseudomonas aeruginosa ATCC 27853, and Mycobacterium intracellulare ATCC 23068. Susceptibility testing was performed using a modified version of the CLSI (formerly NCCLS) methods as previously described. ${ }^{13,14} M$. intracellulare was tested using a modified method according to the method described in the literature. ${ }^{15}$

\section{In vitro Antimalarial Assay:}

Antimalarial activity was determined against chloroquine sensitive (D6, Sierra Leone) and resistant (W2, Indo China) strains of Plasmodium falciparum by measuring plasmodial LDH activity as described earlier. ${ }^{13}$

\section{Cytotoxicity evaluation:}

The cytotoxicity of the compounds was determined towards four cancer cell lines (SK-MEL, KB, BT-549, SK-OV-3) and one noncancer kidney epithelial cell line (LLC-PK $)_{1}$ according to a method described earlier. $^{16}$

\section{Results and discussion}

\section{Chemistry:}

Compound 1 was isolated as needle crystals from methanol. A molecular formula of $\mathrm{C}_{10} \mathrm{H}_{14} \mathrm{~N}_{2} \mathrm{O}_{5}$ was determined by HRESIMS at $\mathrm{m} / \mathrm{z}$ 265.0875 ([M+Na $]^{+}$, calcd for $\left.\mathrm{C}_{10} \mathrm{H}_{14} \mathrm{~N}_{2} \mathrm{O}_{5} \mathrm{Na}, 265.0800\right)$. From NMR spectroscopic data (Table 1) and comparison with the literature, ${ }^{17}$ compound 1 has a deoxyribose moiety attached to a pyrimidine nucleuswith values for deoxyribose moiety at $\delta_{\mathrm{H}} 7.04(1 \mathrm{H}, \mathrm{t}) / \delta_{\mathrm{C}} 85.8$, $\delta_{\mathrm{H}} 5.05(1 \mathrm{H}, \mathrm{m}) / \delta_{\mathrm{C}} 71.9, \delta_{\mathrm{H}} 4.48(1 \mathrm{H}, \mathrm{dd}) / \delta_{\mathrm{C}} 89.3, \delta_{\mathrm{H}} 4.25,4.15(2 \mathrm{H}, \mathrm{dd}) /$ $\delta_{\mathrm{C}} 62.8$ and $\delta_{\mathrm{H}} 2.67(2 \mathrm{H}, \mathrm{m}) / \delta_{\mathrm{C}} 41.9$ while pyrimidine moiety values were at $\delta_{\mathrm{H}} 8.17(2 \mathrm{H}, \mathrm{s}) / \delta_{\mathrm{C}} 137.1$ and $\delta_{\mathrm{H}} 1.88(3 \mathrm{H}, \mathrm{s}) / \delta_{\mathrm{C}} 41.9$ beside $\delta_{\mathrm{C}}$ $165.5, \delta_{\mathrm{C}} 152.4$ and $\delta_{\mathrm{C}} 110.9$. From the above spectroscopic data and comparing with literature, ${ }^{17}$ compound 1 was deduced as thymidine (Figure 1).

Compound 2 was isolated as yellowish amorphous powders. Its molecular formula $\left(\mathrm{C}_{9} \mathrm{H}_{12} \mathrm{~N}_{2} \mathrm{O}_{6}\right)$ was inferred from HRESIMS (negative ion mode) data [ $\mathrm{m} / \mathrm{z} 243.0675$ ([M-H], calcd 243.0617)]. The NMR spectroscopic data (Table 1 ) is closely related to compound 1 except the presence of an olefinic proton at $\delta_{\mathrm{H}} 5.65(1 \mathrm{H}, \mathrm{d}, J=8 \mathrm{~Hz})$ instead of the methyl group at C-5 and additional hydroxyl group at $\mathrm{C}-2^{\prime}\left(\delta_{\mathrm{H}} 4.92(1 \mathrm{H}, \mathrm{m}) / \delta_{\mathrm{C}} 71.6\right)$. Comparing the ${ }^{13} \mathrm{C}$ NMR chemical shifts with those reported in literature, ${ }^{18}$ compound 2 was identified as uridine (Figure 1).

Compound 3 was isolated as white amorphous powders. It has the molecular formula of $\mathrm{C}_{10} \mathrm{H}_{13} \mathrm{~N}_{5} \mathrm{O}_{4}$ that was determined from the HRESIMS data $[\mathrm{m} / z \text { 268.1053 [M+H] }]^{+}$, (calcd 268.1046)]. The analysis of NMR spectroscopic data (Table 1) showed the presence of the following; an oxygenated methylene group, six methines (four of them were found to be oxygenated, while two olefinic) and three quaternary carbons. From its spectroscopic data and comparing with literature, ${ }^{19}$ compound 3 was identified as adenosine (Figure 1).

Compound 4 was isolated as white crystals $(\mathrm{MeOH})$. Its molecular formula $\mathrm{C}_{10} \mathrm{H}_{13} \mathrm{~N}_{5} \mathrm{O}_{4}$ was deduced from HRESIMS (positive ion mode) data $\left[\mathrm{m} / z 269.0879\left([\mathrm{M}+\mathrm{H}]^{+}\right.\right.$, calcd for $\left.\left.\mathrm{C}_{10} \mathrm{H}_{13} \mathrm{~N}_{4} \mathrm{O}_{5}, 268.0886\right)\right]$ and (negative ion mode) $\left[\mathrm{m} / \mathrm{z} 267.0822\left([\mathrm{M}-\mathrm{H}]^{-}\right.\right.$, calcd for $\mathrm{C}_{10} \mathrm{H}_{11} \mathrm{~N}_{4} \mathrm{O}_{5}$, 267.0729)]. The NMR spectroscopic data (Table 1) of compound 4 were similar to compound 3 except that C-6 is attached to oxygen instead of nitrogen. By comparing its spectroscopic data with those reported in literature, ${ }^{17}$ compound 4 was identified as Inosine (Figure $1)$.

Compounds 5-9 were identified by comparison of their spectroscopic characteristics with those previously reported in the literature as 24-methylene cholesterol (5), ${ }^{20,21}$ dihydrocholesterol (6), ${ }^{22}$ cholesterol (7), ${ }^{22}$ oleic acid (8) ${ }^{23}$ and 1,3-palmityl-2-palmitoleoylglycerol (9). ${ }^{24,25}$ Acetylation of compounds $1,2,3,4$ and 5 yielded thymidine $3^{`}, 5^{`}$-diacetate (1-Ac), uridine $2^{\prime}, 3^{`}, 5^{\prime}$-triacetate (2-Ac), adenosine $2^{\prime}, 3^{\prime}, 5^{\prime}$-triacetate (3-Ac), inosine 2',3`,5'-triacetate (2-Ac), cholesterol-3-acetate (5-Ac) and 24-methylene cholesterol-3-acetate (5-Ac), respectively (Figure 1). 
Table I 'H and ${ }^{13} \mathrm{C}$ NMR data for compounds I-4

\begin{tabular}{|c|c|c|c|c|c|c|c|c|}
\hline & I & & 2 & & 3 & & 4 & \\
\hline Position & $\delta \mathrm{X}$ & $\delta \mathrm{H}$ & $\delta \mathrm{X}$ & $\delta$ & $\delta \mathrm{X}$ & $\delta \mathrm{H}$ & $\delta \mathrm{X}$ & $\delta \mathrm{H}$ \\
\hline I & - & - & - & - & - & - & - & - \\
\hline 2 & 152.4 & - & 151.2 & - & 152.4 & $8.17, \mathrm{~s}$ & 146.4 & $8.35, \mathrm{~s}$ \\
\hline 3 & - & - & - & - & - & - & - & - \\
\hline 4 & 137.1 & $8.17, \mathrm{~s}$ & 141.2 & $8.55, \mathrm{~d}(8.0)$ & 149.1 & - & |48.| & - \\
\hline 5 & 110.9 & - & 102.2 & $5.65, \mathrm{~d}(8.0)$ & 119.4 & - & 124.9 & - \\
\hline 6 & 165.3 & - & 163.6 & - & 156.2 & - & 157.1 & - \\
\hline 7 & 13.2 & $1.88, \mathrm{~s}$ & - & - & - & - & - & - \\
\hline 8 & - & - & - & - & 140 & $8.36, \mathrm{~s}$ & 139.2 & $8.09, \mathrm{~s}$ \\
\hline $\mathrm{NH} 2$ & - & - & - & - & - & 7.37, br. & & \\
\hline I & 85.8 & $7.04, \mathrm{t},(6.8)$ & 88.1 & $5.78, \mathrm{t},(5.2)$ & 87.9 & $5.88, \mathrm{~d}(6.4)$ & 87.9 & $5.88, \mathrm{~d}(2.0)$ \\
\hline 2 & 41.2 & $2.67, \mathrm{~m}$ & 70.3 & $3.98, \mathrm{~m}$ & 73.5 & $4.61, \mathrm{~m}$ & 74.6 & $4.50, \mathrm{~m}$ \\
\hline 3 & 71.9 & $5.05, \mathrm{t}(8.6)$ & 74 & $4.04, \mathrm{t}(8.6)$ & 70.7 & $4.15, \mathrm{~m}$ & 70.8 & $4.15, \mathrm{~m}$ \\
\hline 4 & 89.3 & $4.49, \mathrm{~m}$ & 85.3 & $3.85, \mathrm{~m}$ & 85.9 & $3.97, \mathrm{~m}$ & 86.1 & $3.96, \mathrm{~m}$ \\
\hline \multirow[t]{2}{*}{$5^{\prime}$} & 63.4 & $4.15, \mathrm{dd}(3.0,11.6)$ & 61.3 & $3.55, \mathrm{dd}(3.2,12.0)$ & 61.2 & $3.56, \mathrm{dd}(3 . \mathrm{I}, \mathrm{I} .2)$ & 61.7 & $3.57, \mathrm{dd}(4,12)$ \\
\hline & & $4.25, \mathrm{dd}(3.0,11.6)$ & & $3.63, \mathrm{dd}(3.2,12.0)$ & & $3.68, \mathrm{dd}(3.1,12.2)$ & & $3.68, \mathrm{dd}(4,12)$ \\
\hline
\end{tabular}

'H NMR(500 MHz) spectroscopic data $[\delta$ in ppm, mult. $(J$ in $\mathrm{Hz})] \cdot{ }^{13} \mathrm{C}$ NMR(I25 MHz) spectroscopic data $(\delta$ in ppm)

\section{Antiprotozoal activity:}

Antiprotozoal activity of all compounds was tested against Leishmania donovani Promastigote, Leishmania donovani Amastigote, Leishmania donovani Amastigote/THP1 and Trypanosoma brucei. 24-methylene cholesterol (5) showed promising antitrypanosomal activity with $\mathrm{IC}_{50}$ and $\mathrm{IC}_{90}$ values of $3.39,6.69 \mu \mathrm{g} / \mathrm{mL}$, which was comparable to DFMO $(3.58,8.53 \mu \mathrm{g} / \mathrm{mL})$, the positive control (Table 2) (Figure 2). Other compounds tested did not show noticeable activity against the protozoan parasites. A recent study has reported 24-Methylenecyclopropane as new class of steroidal inhibitorsmechanism-based suicide substrates with promising activity against T. Brucei. ${ }^{26}$ It would be interesting to investigate 24-methylene cholesterol as inhibitor of ergosterol biosynthesis as potential drug target. $^{27}$

\section{Antimicrobial activity:}

Antimicrobial activity of the compounds was determined against bacterial strains, Methicillin-resistant Staphylococcus aureus (MRSa), Escherichia coli, Pseudomonas aeruginosa and Mycobacterium intracellulare, as well as against pathogenic fungi including Candida albicans, Aspergillus fumigatus and Cryptococcus neoformans with no significant activity.

\section{Antimalarial activity:}

All the isolated compounds were tested against chloroquinesensitive (D6) and chloroquine-resistant (W2) strains of Plasmodium falciparum by measuring plasmodial LDH activity but, none of the tested compounds showed any activity.

\section{Cytotoxic activity:}

All the isolated compounds were tested against SK-MEL, KB, BT-

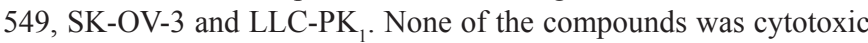
to all the cancer cell lines up to the highest tested concentration of $25 \mu \mathrm{g} / \mathrm{mL}$. However, compound 5 showed cytotoxicity to kidney cells with $\mathrm{IC}_{50}$ value of $23 \mu \mathrm{g} / \mathrm{mL}$. 

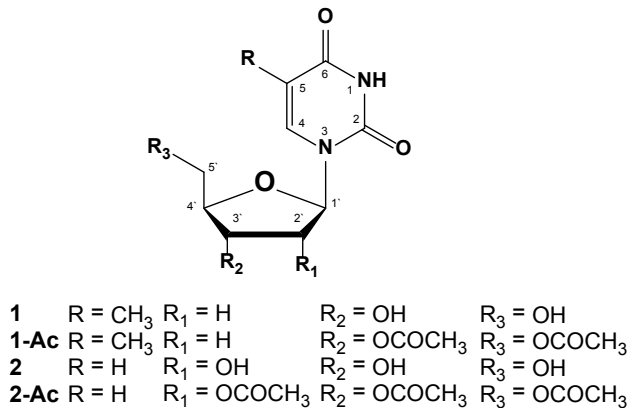

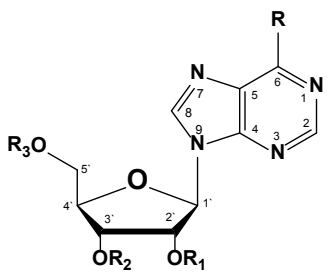

$3 \quad \mathrm{R}=\mathrm{NH}_{2} \mathrm{R}_{1}=\mathrm{H} \quad \mathrm{R}_{2}=\mathrm{H} \quad \mathrm{R}_{3}=\mathrm{H}$ 3-Ac R $=\mathrm{NH}_{2} \mathrm{R}_{1}=\mathrm{COCH}_{3} \mathrm{R}_{2}=\mathrm{COCH}_{3} \mathrm{R}_{3}=\mathrm{COCH}_{3}$ $4 \quad \mathrm{R}=\mathrm{O} \quad \mathrm{R}_{1}=\mathrm{H} \quad \mathrm{R}_{2}=\mathrm{H} \quad \mathrm{R}_{3}=\mathrm{H}$ 4-Ac R = O $\quad \mathrm{R}_{1}=\mathrm{COCH}_{3} \mathrm{R}_{2}=\mathrm{COCH}_{3} \mathrm{R}_{3}=\mathrm{COCH}_{3}$

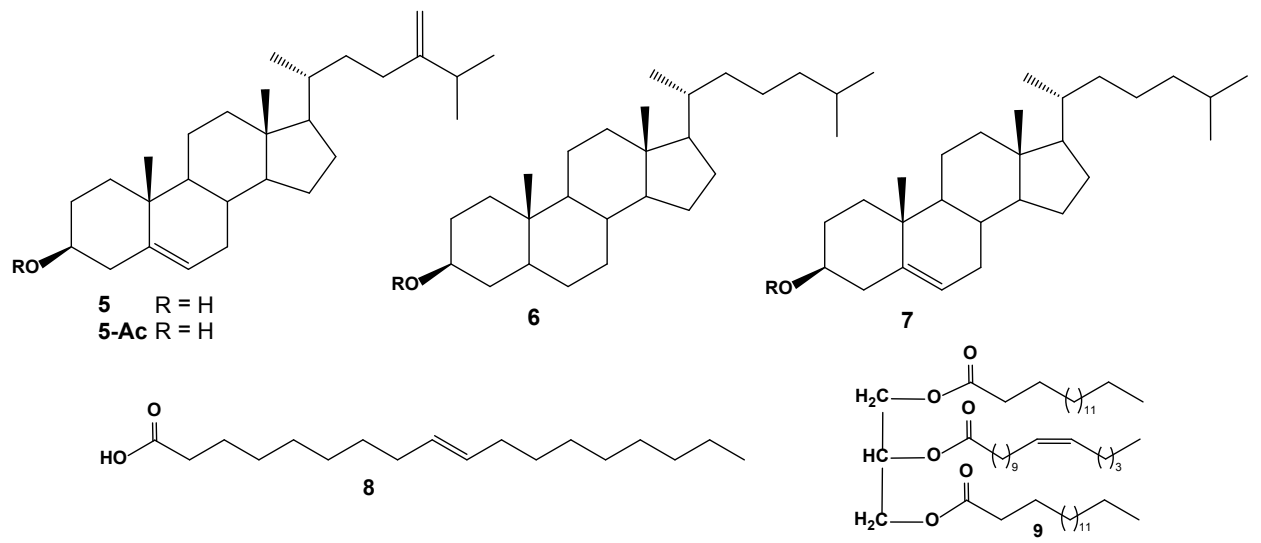

Figure I Chemical structures of the isolated compounds (I-9) and the acetylated compounds (IAc-5Ac).

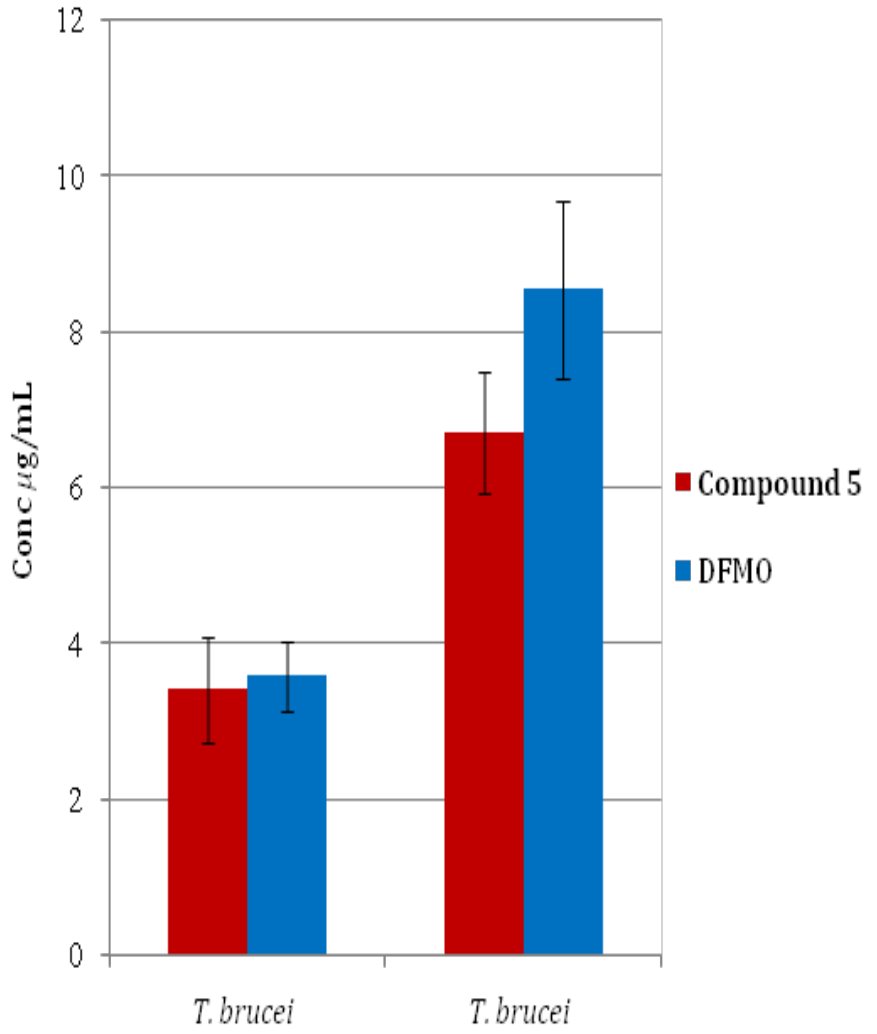

Figure $2 \mathrm{IC}_{50}$ and $\mathrm{IC}_{90}$ values for in vitro activity of compound 5 against Trypanosoma brucei.
Table $2 \mathrm{IC}_{50}$ and $\mathrm{IC}_{90}$ values for in vitro activity of compound 5 against Trypanosoma brucei

\begin{tabular}{lll}
\hline & \multicolumn{2}{l}{ Trypanosoma brucei } \\
\hline Compound & IC $_{50}$ & IC $_{90}$ \\
\hline 5 & $3.39 \pm 0.68 * *$ & $6.69 \pm 0.78 *$ \\
DFMO & $3.58 \pm 0.45$ & $8.53 \pm 1.15$ \\
\hline
\end{tabular}

$\mathrm{IC}_{50}$ and $\mathrm{IC}_{90}(\mu \mathrm{g} / \mathrm{mL})$; DFMO, $\alpha$-difluoromethylornithine; values are expressed as mean \pm S.E.M. $(n=3)$; ${ }^{*} p<0.05$ significant when compared with the corresponding value of the standard group; $* * p>0.05$ non significant when compared with the corresponding value of the standard group; done by independent Student's t-test.

\section{Conclusion}

Nine known compounds were isolated from the Red Sea tunicate Polyclinum constellatum. The structures were elucidated by spectroscopic analysis. The antimicrobial, antimalarial, antiprotzoal, and cytotoxic activities of the isolated compounds were evaluated. Compound 5 displayed good antitrypanocidal activity with $\mathrm{IC}_{50}$ and $\mathrm{IC}_{90}$ of 3.39 and $6.69 \mu \mathrm{g} / \mathrm{mL}$ respectively, and cytotoxicity against LLC-PK 1 with $\mathrm{IC}_{50}$ value of $23 \mu \mathrm{g} / \mathrm{mL}$.

\section{Acknowledgments}

The authors thank Dr. Bharathi Avula, Dr. Mellisa Jacob and Surendra Jain, National Center for Natural Products Research for assistance with the HRESIMS, antimicrobial and antiprotozoal assays respectively and Dr. Tarek Temraz, Marine Science Department, Faculty of Science, Suez Canal University, Ismailia for the taxonomical identification of the marine organism. Thanks are also due to the Egyptian Environmental Affairs Agency (EEAA) for facilitating 
sample collection along the coasts of the Red Sea. Financial support was partially provided by the Egyptian government. Antimicrobial and antiprotozoal biological screenings at the NCNPR are partly supported by the cooperative scientific agreement with USDA-ARS (58-6408-2-0009).

\section{Conflict of interest}

Author declares that there is no conflict of interest.

\section{References}

1. Lemaire P, Piette J. Tunicates: exploring the sea shores and roaming the open ocean. A tribute to Thomas Huxley. Open Biology. 2015;5(6):150053.

2. Nakamura A, Ashino T, Yamamoto M. Structure determination of a very unusual peroxide from solitary ascidians, Phallusia mammillata, Ascidia ahodori, styela pricata and halocynthia roretzi. Tetrahedron Letters. 1991;32(34):4355-4358.

3. Rajesh RP, Ramasamy MS, Murugan A. Anticancer activity of the ascidian polyclinum indicum against cervical cancer cells (HeLa) mediated through apoptosis induction. Med Chem. 2010;6(6):396-405.

4. Bragadeeswaran S, Ganesan K, Sri Kumaran N, et al. Antibacterial and cytotoxic activities of ascidians Polyclinum madrasensis Sebestian, 1952 and Phallusia nigra Savigny, 1816 from Tuticorin Coast of India. World Applied Sciences Journal. 2010;9(12):1387-1391.

5. Bragadeeswaran S, Ganesan K, Sri Kumaran N. Hemolytic activities from ascidian Polyclinum madrasensis Sebestian, 1952 and Phallusia nigra Savigny, 1816 from Tuticorin coast of India. Asian J Applied Sci. 2011;4(6):630-639.

6. Lindquist N, Fenical W, Párkányi L, et al. Polyclinal, a new sulfated polyhydroxy benzaldehyde from the marine ascidian Polyclinum planum. Cell Mol Life Sci. 1991;47(5):503-504.

7. Mpetga JDS, Tene M, Wabo HK, et al. Cytotoxic cycloartanes from the fruits of Caloncoba glauca. Phytochem Lett. 2012;5(1):183-187.

8. Hoshi M, Williams M, Kishimoto Y. Esterification of fatty acids at room temperature by chloroform-methanolic $\mathrm{HCl}-$ cupric acetate. J Lipid Res. 1973;14(5):599-601.

9. Ichihara K, Fukubayashi, Y. Preparation of fatty acid methyl esters for gas-liquid chromatography, J Lipid Res. 2010;51(3):635-640.

10. Manda S, Khan S, Jain S, et al. Synthesis, antileishmanial and antitrypanosomal activities of $\mathrm{N}$-substituted tetrahydro- $\boldsymbol{\beta}$-carbolines. Bioorg med chem lett. 2014;24(15):3247-3250.

11. Räz B, Iten M, Grether-Bühler Y, et al. The Alamar Blue ${ }^{\circledR}$ assay to determine drug sensitivity of African trypanosomes ( $T b$ rhodesiense and $T b$ gambiense) in vitro. Acta Trop. 1997;68(2):139-147.

12. Jain SK, Sahu R, Walker LA, et al. A parasite rescue and transformation assay for antileishmanial screening against intracellular Leishmania donovani amastigotes in THP1 human acute monocytic leukemia cell line. J Vis Exp. 2012;70:e4054.
13. Radwan M, Wanas A, Fronczek F, et al. Polybrominated diphenyl ethers from the marine organisms Lendenfeldia dendyi and Sinularia dura with anti-MRSa activity. Medicinal Chemistry Research. 2015;24(9):3398-3404.

14. Samoylenko V, Jacob M, Khan S, et al. Antimicrobial, antiparasitic and cytotoxic spermine alkaloids from Albizia schimperiana. Nat Prod Comm. 2009;4(6):791-796.

15. Franzblau SG, Witzig RS, McLaughlin JC, et al. Rapid, low-technology MIC determination with clinical Mycobacterium tuberculosis isolates by using the microplate Alamar Blue assay. J Clin Microbiol. $1998 ; 36(2): 362-366$.

16. Zhang Z, Ali Z, Khan SI, et al. Cytotoxic monacolins from red yeast rice, a Chinese medicine and food. Food Chem. 2016;202:262-268.

17. Jones AJ, Grant DM, Winkley MW, et al. Carbon-13 magnetic resonance. XVII. Pyrimidine and purine nucleosides. J Am Chem Soc. 1970;92(13):4079-4087.

18. Still IW, Plavac N, McKinnon DM, et al. Carbon-13 nuclear magnetic resonance spectra of N-, O-, and S-methylated uracil and thiouracil derivatives. Can J Chem. 1978;56(5):725-729.

19. Liu D, Wang S, Zhang L, et al. Chemical composition of $n-\mathrm{BuOH}$ extract of Potentilla anserina L. and its protective effect of EAhy926 endothelial cells under hypoxia. Latin American Journal of Pharmacy. 2011;30:1889-1894

20. Sheu JH, Chang KC, Sung PJ, et al. Chemical Constituents of a Formosan Soft Coral Sinularia sp. J Chin Chem Soc. 1999;46(2):253-257.

21. Shaker KH, Al-wahaibi LH. ${ }^{13} \mathrm{C}$-NMR of steroids from the soft coral $\mathrm{Li}$ tophyton arboreum. Int J Pharm Sci Rev Res. 2016;36(1):149-152.

22. Wilson WK, Sumpter RM, Warren JJ, et al. Analysis of unsaturated C27 sterols by nuclear magnetic resonance spectroscopy. J Lipid Res. 1996;37(7):1529-1555.

23. Mohamed GA, Abd-Elrazek AE, Hassanean HA, et al. New fatty acids from the Red Sea sponge Mycale euplectellioides. Nat Prod Res. 2014;28(14):1082-1090.

24. Miranda-Vilela AL, Grisolia CK, Resck IS, et al. Characterization of the major nutritional components of Caryocar brasiliense fruit pulp by NMR spectroscopy. Quim Nova. 2009;32(9):2310-2313.

25. Cvačka J, Hovorka O, Jiroš P, et al. Analysis of triacylglycerols in fat body of bumblebees by chromatographic methods. J Chromatogr A. 2006;1101(1):226-237.

26. Miller MB, Patkar P, Singha UK, et al. 24-Methylenecyclopropane steroidal inhibitors: A Trojan horse in ergosterol biosynthesis that prevents growth of Trypanosoma brucei. Biochim Biophys Acta. 2017; 1862(3):305-313.

27. Leaver DJ, Patkar P, Singha UK, et al. Fluorinated Sterols Are Suicide Inhibitors of Ergosterol Biosynthesis and Growth in Trypanosoma brucei. Chem Biol. 2015;22(10):1374-1383. 